\title{
Probing the Surface of a Laccase for Clues towards the Design of Chemo-Enzymatic Catalysts
}

\author{
Viviane Robert, ${ }^{[\mathrm{a}]}$ Emanuele Monza, ${ }^{[\mathrm{b}]}$ Lionel Tarrago, ${ }^{[\mathrm{a}]}$ Ferran Sancho, ${ }^{[\mathrm{b}]}$ Anna De Falco, ${ }^{[\mathrm{a}]}$ \\ Ludovic Schneider, ${ }^{[a]}$ Eloïne Npetgat Ngoutane, ${ }^{[a]}$ Yasmina Mekmouche, ${ }^{[a]}$ Pierre \\ Rousselot Pailley, ${ }^{[a]}$ A. Jalila Simaan, ${ }^{[a]}$ Victor Guallar, ${ }^{[b, c]}$ and Thierry Tron ${ }^{*[a]}$
}

In memory of T. Silviu Balaban

\begin{abstract}
Systems featuring a multi-copper oxidase associated with transition-metal complexes can be used to perform oxidation reactions in mild conditions. Here, a strategy is presented for achieving a controlled orientation of a ruthenium-polypyridyl graft at the surface of a fungal laccase. Laccase variants are engineered with unique surface-accessible lysine residues. Distinct ruthenium-polypyridyl-modified laccases are obtained by the reductive alkylation of lysine residues precisely located relative to the $\mathrm{T} 1$ copper centre of the enzyme. In none of these
\end{abstract}

hybrids does the presence of the graft compromise the catalytic efficiency of the enzyme on the substrate 2,2'-azino-bis(3ethylbenzothiazoline-6-sulfonic acid). Furthermore, the efficiency of the hybrids in olefin oxidation coupled to the lightdriven reduction of $\mathrm{O}_{2}$ is highly dependent on the location of the graft at the enzyme surface. Simulated $\mathrm{Ru}^{\prime \prime}-\mathrm{Cu}$ " electron coupling values and distances fit well the observed reactivity and could be used to guide future hybrid designs.

\section{Introduction}

The development of new bio-inspired processes for the sustainable production of chemicals is at the heart of today's grand challenges. The minimal requirements for a (bio)catalyst are: high activity, robustness and ease of production (i.e., low cost). Beyond this scope, specific physicochemical characteristics such as optimal selectivity and activity, solvent tolerance or stability at a given $\mathrm{pH}$ are unlikely to be all inherent properties

[a] Dr. V. Robert, Dr. L. Tarrago, A. De Falco, Dr. L. Schneider,

Dr. E. Npetgat Ngoutane, Dr. Y. Mekmouche, Dr. P. R. Pailley,

Dr. A. J. Simaan, Dr. T. Tron

Aix Marseille Université

Centrale Marseille, CNRS, iSm2 UMR 7313

13397 Marseille (France)

E-mail: thierry.tron@univ-amu.fr

[b] E. Monza, F. Sancho, Prof. V. Guallar

Joint BSC-CRG-IRB Research Program in Computational Biology

Barcelona Supercomputing Centre

Jordi Girona 29, 08034 Barcelona (Spain)

[c] Prof. V. Guallar

ICREA

Passeig Lluís Companys 23, 08010 Barcelona (Spain)

$\square$ Supporting information for this article can be found under: http:// dx.doi.org/10.1002/cplu.201700030. It contains details of the construction of the UNIK variants. Laccase activity assay: standard assay; microtiter plate assay. Kinetic parameters. Enzyme functionalisation. Mass spectrometry. Photoreduction experiments: light sources, filters and settings; effect of light on laccase activity; photoreduction kinetics; evolution of $p$-styrenesulfonate oxidation products. Computational details: homology modelling and system preparation; covalent docking of complex 1 and docking of $\left[\mathrm{Ru}(\mathrm{bpy})_{3}\right]^{2+}$; molecular dynamics and metadynamics; electronic coupling calculations.

This article is part of the "Biofest" Special Issue. To view the complete issue, visit: https://doi.org/10.1002/cplu.v82.4. of an enzyme and are still challenging to obtain in a synthetic catalyst by design. In the case of enzymes, a process-driven customisation is achievable through the combination of molecular evolution techniques and highly efficient expression systems. ${ }^{[1-3]}$ Furthermore, like the cellular post-translational modifications that increase the functional diversity of the proteome (e.g., the covalent addition of functional groups, the formation of intra- or intermolecular bonds or a proteolytic cleavage), the functionality of recombinant enzymes can be refined using well-established techniques of chemical modification of the enzyme surface. ${ }^{[4-7]}$ The literature is abundant with examples of proteins covalently modified with tags of all kinds for different purposes: purification, stabilisation, labelling, or even editing enzyme function. ${ }^{[8-11]}$ Therefore, the combination of surface-located modulators with robust enzymes offers opportunities for developing biomolecule-based catalysts with entirely new sets of functions.

The enzyme laccase (EC1.10.3.2, from plant, fungi, or bacteria) is a robust catalyst largely studied for its potential uses in industrial bleaching processes, organic synthesis applications and in biofuel cells as a cathodic catalyst that reduces dioxygen into water. ${ }^{[12,13]}$ Laccases couple the oxidation of a wide range of organic and inorganic substrates occurring at a surface-located mononuclear centre (one type $1 \mathrm{Cu}^{\prime \prime}$ ion) to the four-electron reduction of dioxygen into water, which occurs at a buried trinuclear centre (TNC, structured between a type 3 pair and type $2 \mathrm{Cu}^{\prime \prime}$ ions) through successive intramolecular electron transfers (ETs). ${ }^{[14,15]}$ Expanding laccase reactivity through their combination with small and diffusible synthetic redox mediators is well documented. ${ }^{[16]}$ Recently, we have in- 
vestigated bimolecular systems by associating the enzyme with palladium complexes (for alcohol oxidation) or ruthenium-polypyridyl photosensitisers (for epoxidation) taking advantage of the driving force of dioxygen reduction $(1.23 \mathrm{~V}$ at $\mathrm{pH} 0) .{ }^{[17,18]}$ However, bimolecular systems are intrinsically limited by diffusion. Today, the well-known topography of their redox centres (there are tens of 3D structures are available in databases) makes laccases perfect candidates for surface-targeted modulation of the enzyme function.

Most tagging procedures are generally unspecific as they are based on a general chemical character (e.g., nucleophilicity) of the side chains of surface amino acids. Amino acids with a reactive function are either naturally abundant at the protein surface (e.g., lysine, K) or might be involved in post-translational modifications (e.g., cysteines). Interestingly, there are only two lysine residues naturally present in the mature sequence of the laccase LAC3 from the fungus Trametes sp. C30. ${ }^{[19]}$ This natural paucity in lysine residues suggests a facile engineering of the enzyme to obtain variants with a unique lysine residue located at a desired position on the protein surface (UNIK variants). We report here on the site-directed reductive alkylation of both LAC3 and two of its UNIK variants with a custom ruthenium-polypyridyl-aldehyde complex, allowing the enzyme photoreduction to be probed from distinct surface locations relative to the redox-centres. Performed alongside experimental measurements, molecular simulations, which have proved recently to be effective in modelling laccase-substrate binding and reactivity, ${ }^{[20,21]}$ help us understand the structure and ET behaviour of such hybrid systems.

\section{Results and Discussion}

\section{Design and expression of UNIK variants}

LAC3 is a typical fungal laccase, ${ }^{[19]}$ recombinant forms of which can be easily expressed either in Saccharomyces cerevisiae for screening purposes or in the filamentous fungus Aspergillus niger for gram-per-litre-scale production. ${ }^{[22,23]}$ We have already challenged the plasticity of this enzyme, ${ }^{[24,25]}$ as well as its robustness in chemo-enzymatic catalysis experiments involving an ET either from a transition-metal catalyst or from photosensitisers. ${ }^{[17,18,26,27]}$ The lac3 cDNA (GenBank AAR00925.1) encodes for 501 residues, among which are lysines K40 and K71 (LAC3 numbering). ${ }^{[19]}$ Therefore, lysine variants of LAC3 (designated UNIK) with a unique reactive amino group precisely located at the enzyme surface can be obtained through the replacement of any codon encoding a surface-located residue by an AAA/G codon (encoding a $\mathrm{K}$ residue) in a library of lac 3 sequences representing the natural variations found at positions 40 and 71. Because functional variants can be easily selected upon expression in yeast, ${ }^{[24]}$ such a surface-specific targeting strategy is potentially a powerful tool to probe the ET between the enzyme surface and its interior (i.e., the metal centres). To illustrate this approach, we prepared UNIK variants graftable in the vicinity of the $\mathrm{T} 1 \mathrm{Cu}^{\text {II }}$ site, at positions almost diametrically opposed to positions $\mathrm{K} 40$ and $\mathrm{K} 71$ originally found at the surface of LAC3 (Figure 1). From an examination of the natural varia-

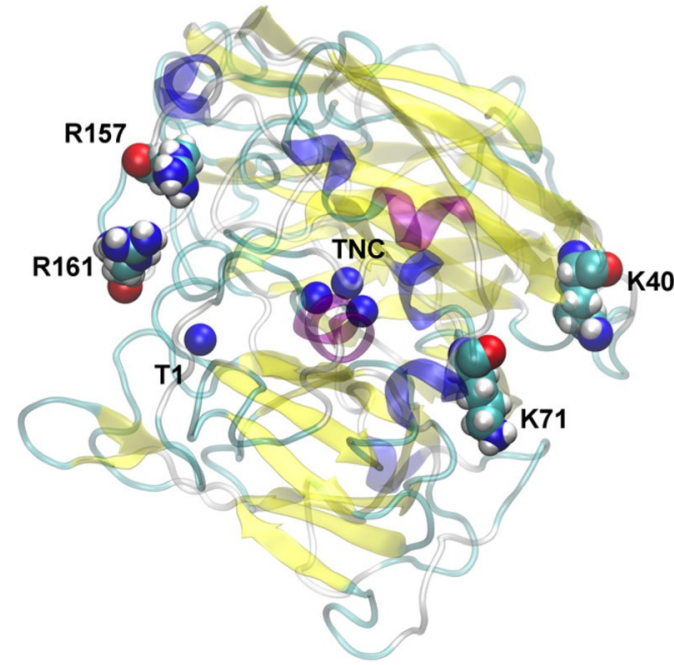

Figure 1. Structural model (ribbon) of LAC3 from Trametes sp. C30. Cu" ions are depicted as blue spheres; amino acids subjected to mutagenesis are labelled (van der Waals volumes, CPK colours).

tion of the amino acid in loops surrounding the $\mathrm{T} 1 \mathrm{Cu}^{\text {II }}$ binding site in laccase sequences from the databases, we initially selected R157 and R161 as residues to substitute for a lysine group. Indeed, the variability at these two positions is high in fungal laccases and residues frequently found include lysines. The construction of UNIK variants included three steps of mutagenesis resulting in successive site-directed replacements of lysine codons 40 and 71 by codons corresponding to the most frequent amino acids found at these positions ( $\mathrm{M}, \mathrm{Q}$ or I at position 40 and $H, A, R$ or $E$ at position 71), followed by the replacement of codons 157 or 161 by a lysine codon. After each step, variants heterologously expressed in S. cerevisiae were screened for laccase activity on the substrate 2,2'-azino-bis(3ethylbenzothiazoline-6-sulfonic acid) (ABTS). The second step yielded enzymes devoid of lysine (NoK); the third step, yielded UNIK $_{157}$ and UNIK ${ }_{161}$ enzymes (see the Supporting Information for construction details). Among the 12 variants obtained for each construction [combinatorial in variations considered for positions 40 (three different residues) and 71 (four different residues)], we selected the $\mathrm{UNIK}_{157}(\mathrm{M} 40, \mathrm{H} 71)$ and $\mathrm{UNIK}_{161}$ (M40, H71) enzymes on the basis of their ABTS oxidation activity relative to that of the parental enzyme LAC3 (see the Supporting Information). Selected enzymes were further produced on a gram-per-litre scale by fermentation of recombinant A. niger strains, as previously described. ${ }^{[23]}$

\section{Functionalisation of LAC3 and UNIK variants}

Primary amino groups present at the surface of proteins are reactive with aldehyde-containing molecules in a reductive alkylation reaction. The UNIK ${ }_{161}(\mathrm{M} 40, \mathrm{H} 71)$ variant has been recently successfully derivatised with a 2,2,2-trifluoro- $N$-(4-oxo-butyl)$\mathrm{N}$-(1-pyren-4-ylmethyl-1H-[1,2,3]triazol-4-ylmethyl)acetamide moiety allowing a precise orientation of the enzyme at a multiwalled carbon nanotube electrode surface. ${ }^{[28]}$ To probe surfaceaccessible lysine residues of both UNIK and LAC3 enzymes we 
selected ruthenium(II)-polypyridine-type chromophores for the following reasons: 1 ) their intense absorption band in the visible spectrum at $\lambda_{\max } \approx 450 \mathrm{~nm}$ (metal-to-ligand charge transfer, $\left.\varepsilon=14500 \mathrm{M}^{-1} \mathrm{~cm}^{-1}\right){ }^{[29]}$ This band is not overlapping the $\lambda_{\max }$ $\approx 605 \mathrm{~nm}$ band characteristics of the $\mathrm{T} 1 \mathrm{Cu}^{\prime \prime}$ site of laccases (ligand-to-metal charge transfer, $\left.\varepsilon=5600 \mathrm{M}^{-1} \mathrm{~cm}^{-1}\right)^{[14]}$ and therefore the $450 / 605$ ratio can be used to evaluate the grafting efficiency; 2) their fluorescence properties $\left(\lambda_{\text {ex }} \approx 450 \mathrm{~nm}\right.$, $\left.\lambda_{\text {em }} \approx 600 \mathrm{~nm}\right){ }^{[13]}$ which are useful to visualise grafted enzymes on SDS-PAGE gels and grafted peptides after digestion and HPLC separation; and 3) their capability to photoreduce laccases upon visible light excitation in the presence of an electron donor. $^{[26]}$

We used a heteroleptic ruthenium(II) complex with one of the bipyridine ligands containing a fused imidazole motif and a benzaldehyde (complex 1 , Scheme 1). This complex is similar to the $\left[R u(b p y)_{3}\right]^{2+}\left(b p y=2,2^{\prime}\right.$-bipyridine) complex we have previously used in bimolecular reactions. ${ }^{[26]}$ LAC3, UNIK $_{157}$ and UNIK $_{161}$ were functionalised with 1 by reductive alkylation in mild conditions (see the Supporting Information). ${ }^{[30]}$<smiles></smiles>

Scheme 1. The structure of complex 1 , $\left[(b p y)_{2} R u(f i m b z l)\right]\left[\mathrm{PF}_{6}\right]_{2} \cdot 2 \mathrm{H}_{2} \mathrm{O}$ (fimbzl $=4-([1,10]$ phenanthroline[5,6- $d]$ imidazol-2-yl)benzaldehyde).

Representative UV/Vis spectra of enzyme-1 hybrids (1-LAC3 and $1-$ UNIK $_{157}$ ) recorded after a gel filtration, are presented in Figure 2. Covalent linkage of complex 1 to the enzymes was addressed by subjecting the grafted laccases to electrophoresis in denaturing conditions. Under UV irradiation ( $360 \mathrm{~nm}$ ) of the gel, the fluorescence of the ruthenium is coincident to the laccase band in samples subjected to reductive alkylation in the presence of complex 1 (Figure 3). At the $\mathrm{pH}$ of the reaction (7.4), lysine groups as well as the amino $\mathrm{N}$ terminus can be

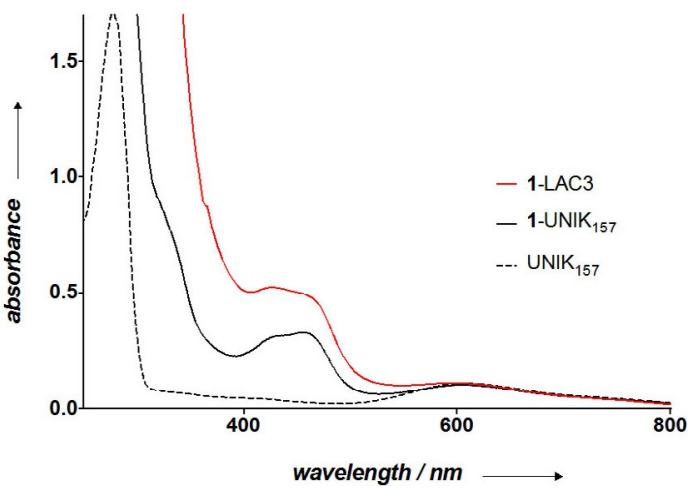

Figure 2. Representative UV/Vis spectra of bare and 1-grafted enzymes. Enzyme concentration ca. $16 \mu \mathrm{M}$ in Britton-Robinson buffer (pH 5).

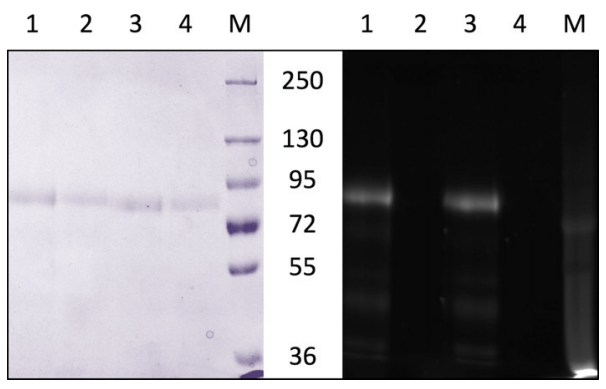

Figure 3. Representative separation of grafted enzymes on a $7 \%$ SDS-PAGE gel. Left panel: white-light irradiation (Coomassie Blue staining); right paneI: UV irradiation (360 nm). M: molecular weight markers. Apparent masses are expressed in kDa. Lane 1: 1-UNIK ${ }_{161}(5 \mu \mathrm{g})$; lane 2: UNIK $_{161}(5 \mu \mathrm{g})$; lane 3: 1-LAC3 $(5 \mu \mathrm{g})$; lane 4: LAC3 $(5 \mu \mathrm{g})$.

subjected to reductive alkylation. Batch after batch, the grafting procedure yielded, respectively, one and two complex 1 moieties per UNIK and LAC3 enzymes (based on the $A_{450} / A_{605}$ ratio, Figure 2 and Table 1).

The complex 1 to laccase ratios were further confirmed by analysing the metal content of the grafted enzymes by inductively coupled plasma mass spectrometry (ICP-MS, Table 1). Eventually, the location of the graft at the surface of enzymes was investigated by Edman degradation and MALDI-TOF MS analysis. The sequencing of each enzyme revealed that the amino terminus of the hybrids was an alanine, the first residue of the mature enzyme, indicating that the $\mathrm{N}$ terminus was not blocked by complex 1 . Trypsin digestion of UNIK ${ }_{161}$ modified

Table 1. Spectroscopic features, sequence data and metal content of the 1-laccase hybrids.

\begin{tabular}{|c|c|c|c|c|c|}
\hline Hybrid & $A_{450} / A_{605}$ & $\begin{array}{l}\text { Amino } \\
\text { terminus }\end{array}$ & $\begin{array}{l}\text { Metal content } \\
\mathrm{Ru} / \mathrm{Cu}^{[\mathrm{a}]}\end{array}$ & 1-labelled trypsic peptide ${ }^{[b]}$ & $\begin{array}{l}\text { Theoretical } \\
\text { mass of peptide }[\mathrm{Da}]^{[\mathrm{c}]}\end{array}$ \\
\hline 1-LAC3 & 4.73 & A & $1.8-2.2 / 4$ & $\begin{array}{l}\text { AAVVMNDQFPGPLIAGNKGDNFQINVIDNLSNSTMLTSTTIHWHGFFQKGT- } \\
\text { NWADGAAFVNQCPISAGNSFLYDFTATDQAGTFWYHSHLSTQYCDGLR }\end{array}$ & 12342.31 \\
\hline $1-\mathrm{UNIK}_{157}$ & 2.97 & A & $1.1 / 4$ & GPMVVYDPDDPHASLYDVDDDSTVITLSDWYHTAAKLGAR & 5129.944 \\
\hline $1-\mathrm{UNIK}_{161}$ & 3.22 & $A$ & $1.2 / 4$ & LGAKFPAGADTLINGLGR & $2578.28(2580.20)$ \\
\hline
\end{tabular}

[a] Measured by ICP-MS. [b] The functionalisation by complex 1 apparently prevents the cleavage of the peptide bond immediately after the lysine residue. [c] $\mathrm{m} / \mathrm{z}$ is given in brackets. 
by complex 1 yielded a single fluorescent peptide corresponding to a singly charged ion of $\mathrm{m} / \mathrm{z} 2580.20$ in the mass spectrum. Both an increment of $722.14 \mathrm{Da}$ in mass (i.e., 738.14-16 Da corresponding to a loss of an oxygen atom in the reductive alkylation reaction) and the characteristic isotopic distribution of ruthenium unambiguously identified K161 as the amino acid grafted with complex 1 in the trypsic peptide of the corresponding 1-UNIK enzyme (Table 1 and see the Supporting Information for details). For LAC3, the theoretical mass of the fluorescent peptide is $12342.31 \mathrm{Da}$ including a mass increment of $1440.28 \mathrm{Da}$ corresponding to two molecules of complex 1. Probably because of the mass of that peptide, data collected so far on the trypsic digestion of LAC3 are unfortunately inconclusive. However, the results of the Edman degradation, the metal quantification and the UV/Vis spectra support a double grafting to an enzyme surface that contains only two lysine residues at positions 40 and 71 . In summary, under our experimental conditions, the reductive alkylation reaction appears selective for the primary amine group of surface-accessible lysine residues. Therefore, the reductive alkylation of UNIK variants warrants a single functionalisation of the laccase surface.

\section{Kinetic characterisation of bare and ruthenium-grafted laccase variants}

The most selective surface functionalisation process would be ineffective if it abolishes the original enzyme function. Laccase is a particularly robust enzyme and experimental conditions used for the reductive alkylation are considered mild compared to other chemical procedures. Nevertheless, the grafting procedure is potentially non-innocent towards enzymes function. Furthermore, the presence of the graft itself at the

\begin{tabular}{|lllll|}
\hline \multicolumn{4}{|c|}{ Table 2. Apparent kinetic parameters for laccase variants on ABTS ${ }^{\text {[a] }}$} \\
Entry & Enzyme & $k_{\text {cat }}\left[\mathrm{s}^{-1}\right]$ & $K_{\mathrm{M}}[\mathrm{M}]$ & $k_{\text {cat }} / K_{\mathrm{M}}\left[\mathrm{s}^{-1} \mathrm{M}^{-1}\right]$ \\
\hline 1 & LAC3 & $246 \pm 1$ & $3.72 \times 10^{-4} \pm 10$ & $6.62 \times 10^{5}$ \\
2 & 1-LAC3 & $173 \pm 7$ & $3.42 \times 10^{-4} \pm 44$ & $5.10 \times 10^{5}$ \\
3 & UNIK $_{157}$ & $247 \pm 1$ & $4.07 \times 10^{-4} \pm 12$ & $6.06 \times 10^{5}$ \\
4 & 1-UNIK $_{157}$ & $188 \pm 2$ & $4.61 \times 10^{-4} \pm 23$ & $4.07 \times 10^{5}$ \\
5 & UNIK $_{161}$ & $204 \pm 3$ & $3.08 \times 10^{-4} \pm 24$ & $6.63 \times 10^{5}$ \\
6 & 1-UNIK $_{161}$ & $195 \pm 1$ & $2.92 \times 10^{-4} \pm 6$ & $6.70 \times 10^{5}$ \\
\hline
\end{tabular}

[a] In Britton-Robinson buffer, pH 5.5, $25^{\circ} \mathrm{C}$; enzyme concentration: ca. $5 \times 10^{-10} \mathrm{M}$; ABTS concentration: $0.1-10 \times 10^{-3} \mathrm{M}$. enzyme surface might interfere with the redox properties of laccases.

The influence of the grafting procedure and/or the presence of the graft on laccase reactivity was evaluated by performing an analysis of the kinetic properties of the bare and ruthenium-grafted laccases. Oxidation kinetic parameters obtained in the presence of ABTS are reported in Table 2 (see Table S2 for data obtained with syringaldazine). First, combinations of the mutations found in the two UNIK variants (i.e., at positions 40 , 71 and 157 or 161) have apparently no major effect on the catalytic efficiency of the variant enzymes as compared to the parental enzyme LAC3 (Table 1, entries 1, 3 and 5). This is consistent with the results of the screening based on ABTS oxidation used to select these variants. Second, the grafting procedure does not compromise the catalytic efficiency of the enzymes. Thus, the reductive alkylation appears to be a valuable method to functionalise the surface of laccases. Third, upon grafting, complex 1 does not significantly interfere with the catalytic efficiencies of the variants. From a study on a bimolecular photocatalytic system made of LAC3 and a ruthenium-polypyridyl complex similar to complex 1 (having a benzoic acid moiety instead of a benzaldehyde), we know that such complexes in solution and in excess can interfere with the oxidation activity of the laccase on the natural substrates. ${ }^{[26]}$ Apparently, grafting helps circumvent this issue by setting both the complex/ enzyme ratio and the location of the complex relative to the substrate oxidation site. In 1-LAC3, the grafted positions K40 and $\mathrm{K} 71$ are almost diametrically opposed to the $\mathrm{T} 1 \mathrm{Cu}^{\text {Il }}$ site ( $C u^{\prime \prime}-\mathrm{Ru}^{\prime \prime}$ distances are between 37 and $45 \AA$, as estimated from molecular simulations, see Table 3 ). The kinetics obtained with 1-LAC3 are consistent with grafts that cannot physically interfere with the substrate oxidation activity of the enzyme. On the contrary, in 1-UNIK hybrids, complex $\mathbf{1}$ is grafted in the vicinity of the $\mathrm{T} 1 \mathrm{Cu}^{\text {Il }}$ site (Figure 1). Therefore, the absence of significant variation in the catalytic efficiencies of grafted variants underlines both the plasticity of the enzyme surface and the overall robustness of the enzyme.

In order to understand the molecular basis of the role of the grafted complex 1 in native catalysis, models of 1-laccase were built. Reductive alkylation between laccase variants and complex 1 was simulated with covalent docking. ${ }^{[31]}$ A 50 ns molecular dynamics simulation was run to refine the binding mode and to take into account the interaction with explicit solvent molecules. Molecular models for $1-\mathrm{UNIK}_{157}$ and $1-\mathrm{UNIK}_{161}$ are presented in Figure 4 (molecular dynamics RMSD plots of both the protein backbone and complex 1 are illustrated in Fig-

\begin{tabular}{|c|c|c|c|c|c|c|c|c|c|c|}
\hline \multirow[t]{3}{*}{$\mathrm{Cu}^{\prime \prime}$ ion } & \multicolumn{4}{|c|}{ 1-LAC3 } & \multicolumn{2}{|c|}{ 1-UNIK ${ }_{161}$} & \multicolumn{2}{|c|}{$1-U_{N} K_{157}$} & \multicolumn{2}{|c|}{$1+\mathrm{LAC} 3$} \\
\hline & & & & & & & & & & \\
\hline & $\mathrm{EC}[\mathrm{eV}]$ & $d[\AA]]$ & $\mathrm{EC}[\mathrm{eV}]$ & $d[\AA]]$ & $\mathrm{EC}[\mathrm{eV}]$ & $d[\AA]$ & $\mathrm{EC}[\mathrm{eV}]$ & $d[\AA]]$ & $\mathrm{EC}[\mathrm{eV}]$ & $d[\AA]$ \\
\hline T1 & $2 \times 10^{-13}$ & 44.9 & $6 \times 10^{-11}$ & 36.8 & $1 \times 10^{-7}$ & 23.5 & $1 \times 10^{-7}$ & 19.8 & $3 \times 10^{-4}$ & 11.2 \\
\hline $\mathrm{T} 2$ & $4 \times 10^{-11}$ & 30.7 & $2 \times 10^{-9}$ & 26.4 & $5 \times 10^{-9}$ & 25.5 & $6 \times 10^{-10}$ & 23.6 & $3 \times 10^{-8}$ & 24.8 \\
\hline Т3 $\alpha$ & $2 \times 10^{-10}$ & 32.6 & $3 \times 10^{-9}$ & 32.0 & $2 \times 10^{-9}$ & 25.8 & $3 \times 10^{-9}$ & 23.3 & $3 \times 10^{-7}$ & 22.1 \\
\hline Тз $\beta$ & $2 \times 10^{-12}$ & 34.5 & $1 \times 10^{-9}$ & 28.8 & $5 \times 10^{-8}$ & 20.5 & $1 \times 10^{-7}$ & 19.3 & $8 \times 10^{-8}$ & 21.8 \\
\hline
\end{tabular}



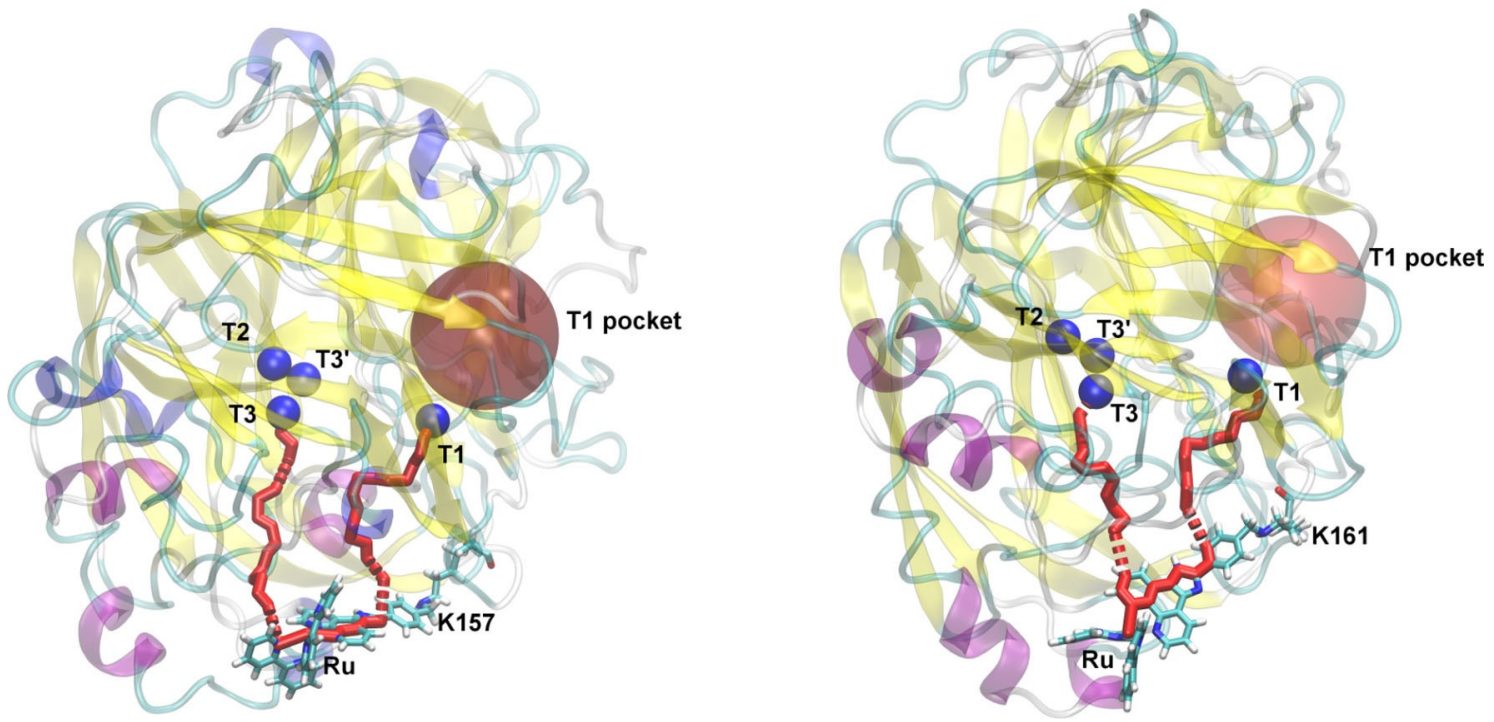

Figure 4. Position of complex 1 in 1-UNIK ${ }_{157}$ (left) and 1-UNIK ${ }_{161}$ (right) obtained from covalent docking plus molecular dynamics simulations. Potential ET pathways are depicted in red. The surface area just above the mononuclear T1 $\mathrm{Cu}$ centre is highlighted as a red sphere.

ure S1). Our models suggest that complex 1 is located at the enzyme surface far from the $\mathrm{T} 1 \mathrm{Cu}^{\prime \prime}$ site entrance (the $\mathrm{Ru}^{\prime \prime}-\mathrm{Cu}$ " distance is $>19 \AA$, see below in Table 3), and likely incapable of hindering the approach of the substrate (Figure 4). Due to this distant location, the extra positive charge added after reductive alkylation (taking into account two positive charges for complex 1) should not alter the oxidation process, in agreement with the kinetic data (Table 2). In the 1-LAC3 model, contributions from positions K40 and K71 were analysed separately for simplicity (Figure S3). In both cases, complex 1 was initially predicted as being partially buried in the cavity adjacent to the TNC centre. In order to better establish the exposed/ buried nature of complex 1, we used an advanced metadynamics sampling technique (see the Supporting Information for details). ${ }^{[34]}$ For both grafting positions, we found that complex 1 is more stable outside the cavity and exposed to the bulk solvent (Figure S2). In summary, the grafting proposed does not compromise the natural catalytic properties of the enzymes. Therefore, LAC3 and UNIK variants can be used to probe the orientation of a graft relative to the catalytic centres.

\section{Photoreduction}

As illustrated by several studies, grafting the surface of a metalloenzyme with ruthenium-polypyridyl complexes is a powerful way to study the transfer of electrons to metal centres embedded in protein matrices. ${ }^{[32]}$ By using a bimolecular system we have recently demonstrated that LAC3 can be reduced by excited photosensitisers in the presence of a sacrificial electron donor. In the first instance, 1-LAC3 and 1-UNIK hybrids were subjected to photoreduction experiments, as previously described. ${ }^{[26,27]}$ In dioxygen-deprived solutions, in the presence of EDTA as electron donor and under constant white light irradiation, all 1-grafted enzymes were progressively reduced as a function of time (Figure 5). After one hour of irradiation in

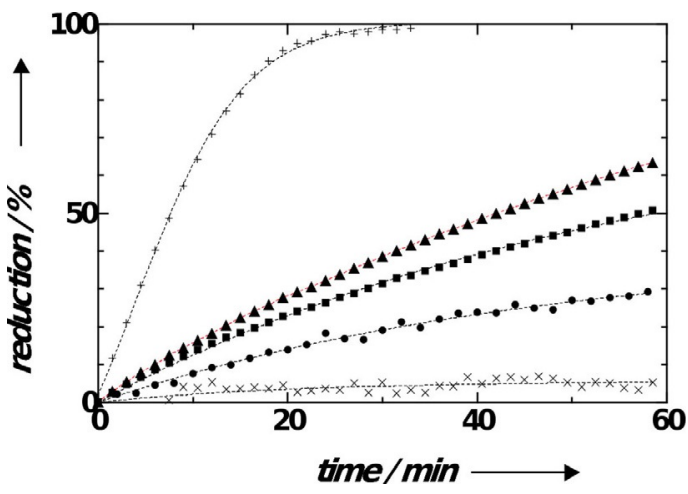

Figure 5. Photoreduction of laccase-ruthenium hybrids. Argon-flushed Britton-Robinson buffer solutions ( $\mathrm{pH}$ 5) containing $3.0 \times 10^{-5} \mathrm{M}$ hybrids in the presence of $1.5 \mathrm{mM}$ EDTA (electron donor). Irradiation was performed with a Dolan-Jenner MI-150 illuminator (Edmund) equipped with a $150 \mathrm{~W}$ EKE Quartz Halogen lamp filtered with a $450 \mathrm{~nm}$ OD 2 longpass filter (Techspec) and guided with an optic fibre (power density of $235 \mathrm{~mW} \mathrm{~cm}^{-2}$ prior to filtration). LAC3 enzyme $(X) ; 1$-LAC3 hybrid $(\lambda)$; 1 -UNIK ${ }_{161}$ hybrid $(v) ; 1-U^{-} N_{15}$ hybrid $(\sigma)$; LAC3 enzyme $+\left[\mathrm{Ru}(\mathrm{bpy})_{3}\right]^{2+}$ bimolecular system (+). See the Supporting Information for the fitted curves. Data points represent an average of three independent measurements.

a degased solution, the extend of reduction (monitored as a time-dependent decrease of the T1 MLCT) of 1-LAC3, 1UNIK $_{161}$ and $1-\mathrm{UNIK}_{157}$ was found to be, respectively approximately $20 \%, 40 \%$ and $50 \%$ on top of the observed photoreduction of the bare enzyme (less than $10 \%$ in a control experiment, Figure 5).

Reduction kinetics of the two 1-UNIK hybrids appear similar to each other and are distinguishable from that of the hybrid 1-LAC3. UNIK hybrids differ from LAC3 in both the number of surface grafts (two in 1-LAC3 and one in 1-UNIK hybrids) and in terms of the area over which complex 1 is grafted (vide supra). From the location of the graft at the enzyme surface, the photoreduction of the hybrids potentially arises from three distinct phenomena: 1) a direct reduction of the $\mathrm{T} 1 \mathrm{Cu}^{\text {ll }}$ site by an 
excited complex $1\left(1^{*}\right) ; 2$ ) a reduction of the $\mathrm{T} 1 \mathrm{Cu}^{\prime \prime}$ site consecutive to the initial reduction of the TNC by $1 *$ (reverse intramolecular reaction); and 3) a photo-induced ET between an excited complex 1 moiety of one hybrid and the $\mathrm{T} 1 \mathrm{Cu}^{\text {ll }}$ site of another (bimolecular reaction). The latter phenomenon, observable for example, in concentrated Ru-P450cam hybrid solutions, ${ }^{[33]}$ is likely to be minor here considering that no significant variation of the reduction rates was observed over a large range of hybrid concentrations (i.e., from 4 to $9.0 \times 10^{-5} \mathrm{M}$ ). Unless considering a long-range ET within the protein matrix, the first proposal seems difficult to apply to the hybrid 1LAC3, leaving potentially the TNC as the primary electron acceptor. On the contrary, in 1-UNIK hybrids, the location of complex 1 in the vicinity of the $\mathrm{T} 1 \mathrm{Cu}^{\text {Il }}$ favours a direct reduction of this centre.

Modelling was again used to address these suppositions on a molecular basis. Ten frames, equispaced in time over the last $10 \mathrm{~ns}$ of molecular dynamics runs, were taken and both the electronic coupling (EC) and distances between the $\mathrm{Ru}^{\prime \prime}$ and $\mathrm{Cu}^{\text {II }}$ ions were calculated (Table 3 ). In agreement with the photoreduction experiment, calculated EC values are similar in the two UNIK variants. As expected, the $\mathrm{T} 1 \mathrm{Cu}^{\prime \prime}$ is probably the first electron acceptor for both hybrids, although it should be noted that $1 *$ might also transfer electrons to one of the T3 $\mathrm{Cu}^{\text {Il }}$ ions, at least in 1-UNIK ${ }_{157}$ (see EC values in Table 3). In the models presented in Figure 4, complex 1, bound either to $\mathrm{K} 157$ or $\mathrm{K} 161$, is located in a shallow depression of the enzyme's surface such that the $\mathrm{Ru}^{\prime \prime}$ ion is almost equidistant to both the T1 and the T3 $\mathrm{Cu}^{\text {II }}$ ions. ${ }^{[37]}$ Then, upon irradiation, ET occurs between metal centres 20-25 $\AA$ away from each other (long-range ET). In 1-LAC3, the distances obtained from molecular models suggest that 1 * might potentially transfer electrons most favourably to the TNC and with a relative higher efficiency from position 71 (Table 3). Here, the metal-to-metal distance ( $\mathrm{Ru}^{\prime \prime}-\mathrm{Cu}$ " $d \approx 30 \AA$ ) is even higher than in 1 -UNIK hybrids and this correlates with the slower kinetics of photoreduction (Figure 5).

Overall, the kinetics of photoreduction measured for 1-grafted enzymes are much slower than those obtained with the bimolecular system consisting of LAC3 and a $\left[\mathrm{Ru}(\mathrm{bpy})_{3}\right]^{2+}$ complex (Figure 5). In order to compare EC between these two configurations, the bimolecular system was simulated by noncovalently docking a $\left[\mathrm{Ru}(\mathrm{bpy})_{3}\right]^{2+}$ complex into the $\mathrm{T} 1 \mathrm{Cu}^{\prime \prime}$ cavity, followed by electronic coupling calculations. The most favourable location of the $\left[\mathrm{Ru}(\mathrm{bpy})_{3}\right]^{2+}$ complex at the enzyme surface (Figure 6) is similar to that earlier obtained by Monte Carlo simulations by Kurzeev et al. for a cyclometalated complex of ruthenium used as a laccase substrate. ${ }^{[35]}$ In the model presented in Figure 6, the Ru"-to-T1 Cu" distance is half that calculated for grafted UNIKs (Table 3). Furthermore, EC in the bimolecular system is three orders of magnitude larger than in grafted systems, which is consistent with its faster $\mathrm{T} 1 \mathrm{Cu}^{\prime \prime}$ reduction. These calculations suggest that a faster $\mathrm{T} 1 \mathrm{Cu}^{\prime \prime}$ reduction should be obtained by any design that reduces the Ru"to-T1 Cull distance in UNIK variants grafted with a ruthenium complex, for example, a graft bearing a shorter bipyridine substituent and/or varying the grafting point at the enzyme sur-

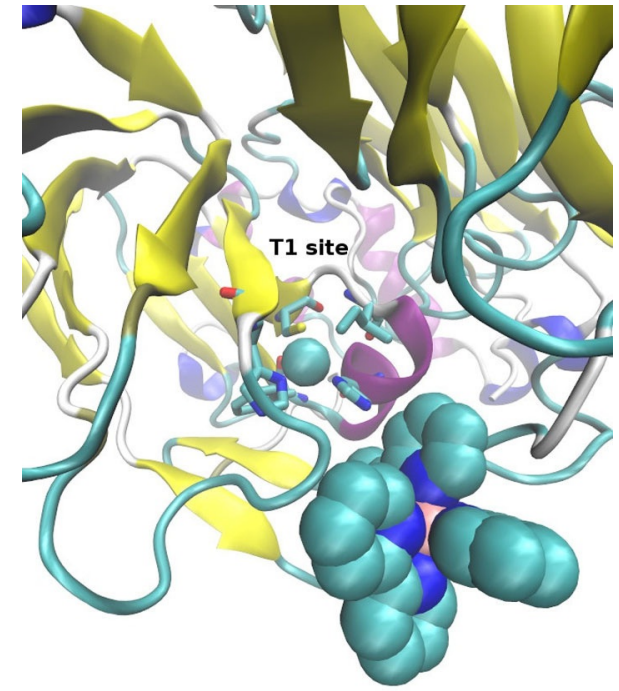

Figure 6. Position of a $\left[\mathrm{Ru}(\mathrm{bpy})_{3}\right]^{2+}$ complex in front of the $\mathrm{T} 1$ copper centre obtained from non-covalent docking

face. On the other hand, it is interesting to compare the modest efficiency of the $\mathrm{T} 1 \mathrm{Cu}$ " photoreduction observed with the 1-UNIK hybrid with the large benefit obtained from a pyrene-UNIK ${ }_{161}$ hybrid in the operation of a laccase biocathode. ${ }^{[28]}$ Both systems comply with a standard functioning of the enzyme, that is, a cumulative one-electron reduction of the four $\mathrm{Cu}^{\prime \prime}$ ions. Strategies for the functionalisation of the UNIK ${ }_{161}$ variant being identical, differences in performance probably arise from the contact area between the material delivering electrons (carbon nanotube surface vs. a ruthenium-polypyridyl complex) and the enzyme surface. This strongly supports that a faster $\mathrm{T} 1 \mathrm{Cu}^{\text {II }}$ photoreduction can be obtained by varying the grafting point in 1-UNIK hybrids.

\section{Photocatalysis}

We have recently described the first photo-oxidation of olefins coupled to the light-driven reduction of $\mathrm{O}_{2}$ by a $\left[\mathrm{Ru}(\mathrm{bpy})_{3}\right]^{2+}$ -laccase bimolecular system. ${ }^{[18]}$ With such a minimal system, olefins oxidation probably occurs through a radical mechanism in which $\mathrm{O}_{2}$ acts both as a renewable electron acceptor and as $\mathrm{O}$ atom donor (Scheme 2).

To complete the present characterisation of 1-grafted enzymes, the ability of 1-LAC3 and 1-UNIK enzymes to oxidise $p$ styrenesulfonate was evaluated. For simplicity, of the two UNIK enzymes, only 1-UNIK ${ }_{161}$ was evaluated as it appeared from calculations that complex 1 might be electronically coupled equally to both the Cull T1 and the TNC centres in 1-UNIK ${ }_{157}$ (Table 3). Upon irradiation, 1-grafted systems catalysed the formation of $p$-styrenesulfonate oxidised species as monitored by ${ }^{1} \mathrm{H}$ NMR spectroscopy (Table 4).

Substantial amounts of oxidation products (the epoxide and the corresponding diol and aldehyde) were detected in the aerated mixture of the $1-\mathrm{UNIK}_{161}$ system. ${ }^{[38]}$ By contrast, photooxidation of $p$-styrenesulfonate in the presence of 1-LAC3 yielded only approximately one-sixth of the amount of prod- 


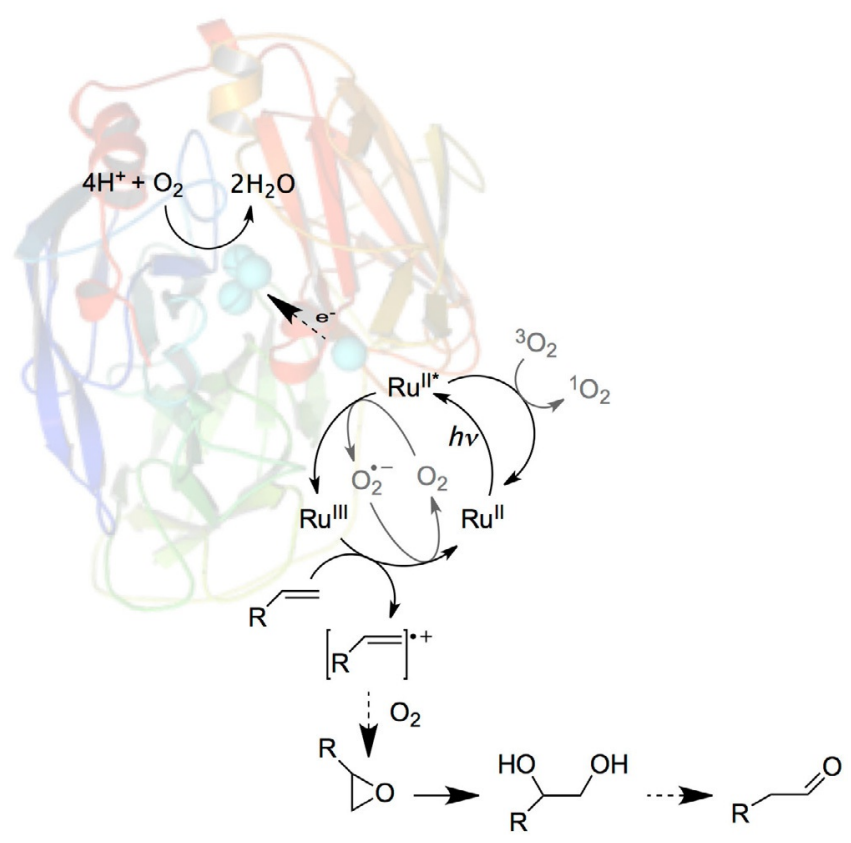

Scheme 2. Photo-oxidation of olefins coupled to the light-driven reduction of $\mathrm{O}_{2}$ by a Ru-polypyridyl complex-laccase. ${ }^{[18]}$ The paths depicted in grey do not lead to product formation in the absence of enzyme. Ribbon model of laccase: $\mathrm{Cu}$ ions are depicted as cyan spheres.

Table 4. $p$-Styrenesulfonate oxidation. ${ }^{[a]}$

\begin{tabular}{|c|c|c|c|c|}
\hline System & \multicolumn{3}{|c|}{ Products $\times 10^{-6} \mathrm{M}$} & Total $\times 10^{-6} \mathrm{M}$ \\
\hline & 分 & $\mathrm{HO} \quad \mathrm{OH}$ & $\mathrm{R}^{\prime=0}$ & \\
\hline $1+\mathrm{LAC} 3$ & $145 \pm 25$ & $140 \pm 15$ & $55 \pm 25$ & 340 \\
\hline 1-LAC3 & n.d. & n.d. & $70 \pm 5$ & 70 \\
\hline $1-$ UNIK $_{161}$ & $150 \pm 20$ & $160 \pm 27$ & $80 \pm 10$ & 390 \\
\hline
\end{tabular}

[a] Conditions: $24 \mathrm{~h}$ irradiation with filtered white LED light (ca. $\left.5 \mathrm{~mW} \mathrm{~cm}^{-2}, 450 \mathrm{~nm}<\lambda<700 \mathrm{~nm}\right) ;[1]=[\mathrm{LAC} 3]=[1-\mathrm{LAC} 3]=\left[1-\mathrm{UNIK}_{161}\right]=$ $30 \times 10^{-6} \mathrm{M}$ relative to the enzyme, $[p$-styrenesulfonate $]=10 \times 10^{-3} \mathrm{M} ; \mathrm{R}=$ phenyl sulfonate; deuterated phosphate buffer, pH 6.0, $T=25^{\circ} \mathrm{C}$. n.d.: not detected; in the absence of light, enzyme or dioxygen, no products were detected. Mean of three independent experiments.

ucts obtained with 1-UNIK 161 (Table 4). Therefore, with two units of complex 1 grafted to $180^{\circ}$ from the T1 centre the 1 LAC3 system is poorly active as a photocatalyst. Altogether, the behaviour of the two hybrid systems as photocatalysts correlates well with $\mathrm{Ru}^{\prime \prime}-\mathrm{Cu}$ " EC values calculated for 1-LAC3 that are consistently lower than those calculated for $1-\mathrm{UNIK}_{161}$ (Table 3).

As for the bimolecular system (Table 4, entry 1 ), use of the 1-UNIK ${ }_{161}$ system led to the accumulation of a primo formed epoxide in a reaction previously shown to be limited by $\mathrm{O}_{2}{ }^{[18]}$ The initial formation of an enyl radical cation is likely followed by the insertion of one $\mathrm{O}$ atom from $\mathrm{O}_{2}$ into the electron-deficient $p$-styrenesulfonate radical (Scheme 2). ${ }^{[18]}$ According to this reaction scheme, $3.90 \times 10^{-4} \mathrm{M}$ of products obtained here with $1-$ UNIK $_{161}$ necessitated a minimum of $3.00 \times 10^{-4} \mathrm{M}$ of $\mathrm{O}_{2}$ from which one-third accounts for a four-electron reduction into water and two-thirds for a subsequent $\mathrm{O}$ atom insertion. This concentration of $\mathrm{O}_{2}$ is slightly greater than that of the dioxygen dissolved in the solution before irradiation (ca. $2.50 \times$ $10^{-4} \mathrm{M}$ ) suggesting that some $\mathrm{O}_{2}$ was obtained after dissolution from the gas phase. So, under photocatalytic conditions the grafted system appears susceptible to follow a regime similar to that of the bimolecular one (Table 4, entry 1 ). ${ }^{[18]}$ At this point, both photoreduction experiments and calculated EC values suggest that $1-\mathrm{UNIK}_{161}$ and $1-\mathrm{UNIK}_{157}$ constructions are suboptimal. However, setting both the complex/enzyme ratio and the location of the complex at the enzyme surface, we readily addressed the major issues intrinsic to the bimolecular system: 1) the need to maintain a relatively high concentration of both partners to favour intermolecular ET reactions; 2) the dependence on a high sensitiser-to-laccase ratio to improve yields; and 3) the rapid inhibition of the activity of the laccase for the oxidation of the natural substrate at relatively low sensitiser concentration. ${ }^{[18,26]}$ Therefore, building on the concept of UNIK enzymes, it is worth investing in the development of new grafts and/or in the design of new variants allowing to decrease the Ru"-to-T1 Cu" distance in order to improve the efficiency of the photocatalyst. Such developments are largely more promising than developing the bimolecular system.

\section{Conclusion}

The lysine-free laccase we created in this study allows the design of single surface-located lysine variants, designated UNIKs, and the precise engineering of the enzyme surface by post-functionalisation. The functionalisation of different areas of the enzyme surface is easily obtained by reductive alkylation without compromising the enzyme core function, that is, the intramolecular ET and dioxygen reduction. Importantly, UNIKs are produced on a gram-per-litre scale by fermentation of recombinant A.niger strains, ensuring a comfortable physicochemical characterisation of the grafted enzymes, as well as a non-compromised future use of these enzymes as biocatalysts. Using a ruthenium photo-sensitiser, we demonstrate that this strategy offers valuable tools to probe the ET between the enzyme surface and both the T1 and the TNC copper centres located in its interior. The computed Ru"-to-Cu" centre distances correlate well with the photoreducibility and in turn with the reactivity of the grafted enzymes. Overall, results obtained from this study allow a better understanding of the system from a fundamental point of view. From this experimental ground, we believe that molecular simulations can guide the design of improved hybrid biocatalysts as well as the precise orientation of the enzyme at a material surface to obtain smart materials.

\section{Experimental Section}

The $\left[\mathrm{Ru}(\mathrm{bpy})_{3}\right]^{2+}$ complex was purchased from Sigma-Aldrich. $\left[(\text { bpy })_{2} \mathrm{Ru}\right.$ (fimbzl)] $\left[\mathrm{PF}_{6}\right]_{2} \cdot 2 \mathrm{H}_{2} \mathrm{O}$ [where fimbzl $=4-([1,10]$ phenanthroline[5,6-d]imidazol-2-yl)benzaldehyde] was synthesised according to the procedure described by Gholamkhass and co-workers. ${ }^{[36]}$ Oxygen consumption was measured by polarography using 
a model 781 oxygen meter (Strathkelvin Instruments, Motherwell, UK) with a micro Clark electrode fitted to a temperature-controlled glass chamber. Irradiation of the sample was performed through the glass chamber. Catalytic tests were performed in air on the bench in $2 \mathrm{~mL}$ vials.

\section{Acknowledgements}

L.S. was the recipient of a Ministère de l'Education Nationale fellowship. This study was supported by grants from the Agence Nationale de la Recherche (ANR-09-BLANC-0176 and ANR-15CE07-0021-01) and from the Ministerio de Economía, Industria y Competitividad (CTQ2016-79138-R). We thank Elise CourvoisierDezord from the Plateforme AVB (AMU): Analyse et Valorisation de la Biodiversite and Yolande Charmasson for help in the production of the recombinant enzymes, as well as Pascal Mansuelle and Régine Lebrun from the Plateforme Protéomique (CNRS$A M U)$ for help in acquiring mass spectrometry data.

\section{Conflict of interest}

The authors declare no conflict of interest.

Keywords: electron transfer - enzyme models - multi-copper oxidase surfaces $\cdot$ photosensitisers $\cdot$ targeted functionalisation

[1] C. A. Denard, H. Ren, H. Zhao, Curr. Opin. Chem. Biol. 2015, 25, 55-64.

[2] W. H. Brondyk, Methods Enzymol. 2009, 463, 131-147.

[3] C. Elena, P. Ravasi, M. E. Castelli, S. Peiru, H. G. Menzella, Front. Microbiol. 2014, 5, 21.

[4] M. G. Roig, J. F. Kennedy, Critic. Rev. Biotech. 1992, 12, 391-412.

[5] J. Eyzaguirre, Biol. Res. 1996, 29, 1-11.

[6] G. DeSantis, J. B. Jones, Curr. Opin. Biotechnol. 1999, 10, 324-330.

[7] B. G. Davis, Curr. Opin. Biotechnol. 2003, 14, 379-386.

[8] T. Montes, V. Grazu, F. Lopez-Gallego, J. A. Hermoso, J. M. Guisan, R. Fernandez-Lafuente, Biomacromolecules 2006, 7, 3052-3058.

[9] V. Stepankova, S. Bidmanova, T. Koudelakova, Z. Prokop, R. Chaloupkova, J. Damborsky, ACS Catal. 2013, 3, 2823-2836.

[10] J. E. Moses, A. D. Moorhouse, Chem. Soc. Rev. 2007, 36, 1249-1262.

[11] C. D. Spicer, B. G. Davis, Nat. Commun. 2014, 5, 4740.

[12] T. Tron in Encyclopedia of Metalloproteins (Eds.: R. H. Kretsinger, V. N. Uversky, E. A. Permyakov), Springer, New York, 2013, pp. 1066-1070.

[13] D. M. Mate, M. Alcalde, Microb. Biotechnol. 2016, DOI: 10.1111/17517915.12422.

[14] E. I. Solomon, M. J. Baldwin, M. D. Lowery, Chem. Rev. 1992, 92, 521 542.

[15] A. J. Augustine, C. Kjaergaard, M. Qayyum, L. Ziegler, D. J. Kosman, K. O. Hodgson, B. Hedman, E. I. Solomon, J. Am. Chem. Soc. 2010, 132, 60576067.

[16] O. V. Morozova, G. P. Shumakovich, S. V. Shleev, Ya. I. Yaropolov, Appl. Biochem. Microbiol. 2007, 43, 523-535.
[17] Y. Mekmouche, L. Schneider, P. Rousselot-Pailley, B. Faure, A. J. Simaan, C. Bochot, M. Reglier, T. Tron, Chem. Sci. 2015, 6, 1247-1251.

[18] L. Schneider, Y. Mekmouche, P. Rousselot-Pailley, A. J. Simaan, V. Robert, M. Reglier, A. Aukauloo, T. Tron, ChemSusChem 2015, 8, 3048-3051.

[19] A. Klonowska, C. Gaudin, M. Asso, A. Fournel, M. Reglier, T. Tron, Enz. Mic. Tech. 2005, 36, 34-41.

[20] E. Monza, M. F. Lucas, S. Camarero, L. C. Alejaldre, A. T. Martínez, V. Guallar, J. Phys. Chem. Lett. 2015, 6, 1447-1453.

[21] I. Pardo, G. Santiago, P. Gentili, F. Lucas, E. Monza, F. J. Medrano, C. Galli, A. T. Martínez, V. Guallar, S. Camarero, Catal. Sci. Technol. 2016, 6, $3900-$ 3910.

[22] V. Robert, Y. Mekmouche, P. R. Pailley, T. Tron, Curr. Genomics 2011, 12, $123-129$.

[23] Y. Mekmouche, S. Zhou, A. M. Cusano, E. Record, A. Lomascolo, V. Robert, A. J. Simaan, P. Rousselot-Pailley, S. Ullah, F. Chaspoul, T. Tron, J. Biosci. Bioeng. 2014, 117, 25-27.

[24] A. M. Cusano, Y. Mekmouche, E. Meglecz, T. Tron, FEBS J. 2009, 276, $5471-5480$.

[25] Y. Liu, A. M. Cusano, E. C. Wallace, Y. Mekmouche, S. Ullah, V. Robert, T. Tron, Int. J. Biol. Macromol. 2014, 69, 435-441.

[26] A. J. Simaan, Y. Mekmouche, C. Herrero, P. Moreno, A. Aukauloo, J. A. Delaire, M. Reglier, T. Tron, Chem. Eur. J. 2011, 17, 11743-11746.

[27] T. Lazarides, I. V. Sazanovich, A. J. Simaan, M. C. Kafentzi, M. Delor, Y. Mekmouche, B. Faure, M. Reglier, J. A. Weinstein, A. G. Coutsolelos, T. Tron, J. Am. Chem. Soc. 2013, 135, 3095-3103.

[28] N. Lalaoui, P. Rousselot-Pailley, V. Robert, Y. Mekmouche, R. Villalonga, M. Holzinger, S. Cosnier, T. Tron, A. Le Goff, ACS Catal. 2016, 6, 1894 1900.

[29] K. Kalyanasundaram, Coord. Chem. Rev. 1982, 46, 159-244.

[30] J. M. McFarland, M. B. Francis, J. Am. Chem. Soc. 2005, 127, $13490-$ 13491.

[31] K. Zhu, K. W. Borrelli, J. R. Greenwood, T. Day, R. Abel, R. S. Farid, E. Harder, J. Chem. Info. Model. 2014, 54, 1932-1940.

[32] a) C. Mayer, D. G. Gillingham, T. R. Ward, D. Hilvert, Chem. Commun. 2011, 47, 12068-12070; b) J. R. Winkler, H. B. Gray, Chem. Rev. 1992, 92, 369-379; c) O. Kokhan, N. S. Ponomarenko, P. R. Pokkuluri, M. Schiffer, K. L. Mulfort, D. M. Tiede, J. Phys. Chem. B 2015, 119, 7612-7624; d) M. E. Ener, Y.-T. Lee, J. R. Winkler, H. B. Gray, L. Cheruzel, Proc. Natl. Acad. Sci. USA 2010, 107, 18783-18786.

[33] J. Contzen, S. Kostka, R. Kraft, C. Jung, J. Inorg. Biochem. 2002, 91, 607617.

[34] A. Laio, M. Parrinello, Proc. Natl. Acad. Sci. USA 2002, 99, 12562-12566.

[35] S. A. Kurzeev, A. S. Vilesov, T. V. Fedorova, E. V. Stepanova, O. V. Koroleva, C. Bukh, M. J. Bjerrum, I. V. Kurnikov, A. D. Ryabov, Biochemistry 2009, 48, 4519-4527.

[36] B. Gholamkhass, K. Koike, N. Negishi, H. Hori, T. Sano, K. Takeuchi, Inorg. Chem. 2003, 42, 2919-2932.

[37] The T3 nomenclature follows that proposed in Augustine et al., Ref. [15].

[38] At the $\mathrm{pH}$ of the reaction it is expected that the epoxide unambigously spontaneously into a diol that can be itself subject to photo-oxidation into an aldehyde.

Manuscript received: January 25, 2017

Revised: February 2, 2017

Accepted Article published: February 3, 2017

Final Article published: March 2, 2017 